\title{
The Impact of Emerging Renewable Energy on Capacity Mechanisms in Power Systems and Expert Opinion
}

\author{
M.R. TUR
}

\begin{abstract}
With the increasing energy demand, the growing capacity of renewable energy sources and the impact of developing competition, it is desirable to manage the market with appropriate investments along with the electricity market and optimum load distribution. In line with this demand, supply security and energy quality play an important role day by day. This includes the production capacity and the long-term security of the system, reflecting the system's ability to stand in unexpected events and sudden load changes. The demand side seems to have insufficient support to the market for new capacity planning to ensure this coverage. This problem can be solved by producing additional capacity. Basically, it is aimed to reduce investment risk for production companies and / or investors and to provide higher supply security and lower price fluctuations to consumers. The concern of not investing in electricity generation capacity to meet the maximum load level has led to investments in capacity utilization in the form of capacity mechanisms of developed and developing states. In this study, an academic analysis of the capacity mechanism of the renewable energy resources and the capacity analysis of the capacity mechanism were made and expert opinions were presented, the latest developments in the energy market were examined and the reliability solutions that could be appropriate to the national electricity market were proposed.
\end{abstract}

Index Terms - capacity mechanism, electricity market, operation reserves, power quality, supply security.

\section{INTRODUCTION}

$\mathrm{P}$ OWER MARKETS are experiencing major changes in their investments in supply security and production capacity along with the search for improved technology and comfort. Together with these developments, there are increasing requirements for reserve production capacity. Production capacity varies depending on the increasing share of variable renewable energy sources (such as wind and solar energy) in line with the needs developed. In addition, these plants cause load factors due to shorter and more variable operating times. Thus, in some periods, the peak load on the

MEHMET RIDA TUR, is with Department of Electrical and Energy University of Batman University, Batman, Turkey,(email:mrida.tur@batman.edu.tr).

(iD https://orcid.org/0000-0001-5688-4624

Manuscript received June 11, 2019; accepted July 2, 2019.

DOI: $10.17694 /$ bajece. 575097 demand side cannot be met and in such cases the limits on how much electricity prices may increase may not be profitable. The increasing share of the electricity market reduces the wholesale electricity prices in a competitive market. This is mainly due to the fact that the marginal cost of variable renewable energies is low or close to zero. Therefore, the profitability of these power plants is decreasing due to the fact that both the working hours are variable and the wholesale prices are low. With the formation of trends, electricity services lack a comprehensive incentive to invest in new generation capacities. This situation is generally referred to as "the problem of lost money". Thus, only the best available power plants used during short periods of peak demand can be used. In the EU electricity sector, as in the electricity sectors of other countries, although generally characterized by excess capacity supply, capacity shortages may occur in case of high demand from low-capacity power plants (due to lack of wind or sun, for example). This leads to concerns that there will be insufficient production capacity in relation to the load distribution to ensure the safety of my electricity supply. The regulatory mechanism should review the main criteria to be considered in the design $[1,2]$. In addition to production resources, energy storage, demand side management, and flexible demand sources (demand side response) can also contribute to resource adequacy. All this determines the power system's ability to ensure the reliability of the electricity supply. Capacity mechanisms are generally argued to help reduce the cost of large-scale wind energy development to reduce the likelihood of loss of load As a result of optimization, it is emphasized the importance of the capacity mechanism by identifying the most suitable type of heating system in terms of the heat load density in the unit area [3-5]. This mechanism is defined as the administrative measure to ensure the desired level of supply security by charging production plants for the availability of resources.

The Energy Market is considered to be an important part of the EU 2020 strategy, as it is recognized as an important means of providing economic, safe and sustainable electricity supply in the future [6]. Basically, it aims to increase competition by opening national markets to foreign participants, thereby increasing supply security and cost efficiency [7-10]. In addition, the European Commission has recently raised concern that these objectives could be harmed by weakly harmonized national market design changes across Europe [11]. In addition, non-coordinated capacities may disrupt cross-border trade and hinder the success of the Domestic Electricity Market in Europe [12,13]. 


\section{CAPACITY MECHANISM}

Our national power system in January 2018, the rules regarding the capacity mechanism to be operated by Turkish Electricity Transmission Corporation (TEIAS) were determined in order to establish an adequate installed power capacity, including the reserve capacity required for supply security in the electricity market, and / or to maintain reliable installed power capacity for long-term system security. At the same time, in the light of concerns over energy resource adequacy, many countries, particularly EU Member States, have introduced capacity mechanisms. In the literature, alternate solutions are discussed consecutively in order to reach the capacity adequacy adopted in different markets. These solutions are the public offering of strategic capacity reserves, payments and capacity obligations for these capacities $[14,15]$. These mechanisms consist of measures to meet the electricity production capacity in order to meet the demand in the long term and medium term. Basically, two such capacity mechanisms are needed to ensure that the reserve production capacity is economically feasible, directly linked to the organization of the electricity market. The availability of battery energy storage systems to be used in the capacity mechanism in the network is taken into account and further analyzes have been carried out to take into account the overvoltage reduction by shaving the photovoltaic production at the highest level [16-18]. Basically, this capacity includes the capacity to take into account the capacity of the plants, the priorities to be allocated to the domestic resources, the annual budget based on the capacity payments, the budget to be used for the budget payments, the calculation of the cost components for the capacity payments, the capacity to be taken into the capacity It should be determined by including the procedures and principles regarding the calculation of the payments and the obstacles to payment. Whether capacity mechanisms are required or only in a time-based market, variant rare pricing can provide sufficient incentives to provide backup capacity. Taking into account the fact that the cooperation between countries can increase the cost efficiency by providing cooperation. Another important issue is the optimum geographical scope of capacity markets. However, as long as a limited amount of electricity can flow between the cross-border networks due to a limited interconnection capacity, a capacity mechanism between countries is not possible $[19,20]$.

\section{TYPES OF CAPACITY MECHANISMS USED IN THE POWER MARKET}

The Energy Regulators Cooperation Agency (ACER) states that there are six types of capacity mechanisms as shown in Figure 1 [21]. Decision-making unit policy makers in unitcentered mechanisms. They make decisions about the size of the capacity volume. In addition, policy-makers allow price setting based on marketing. In price-based mechanisms, policy makers also take an active role. Here, after determining the price, the management allows investors to decide that they are willing to invest in a certain price.

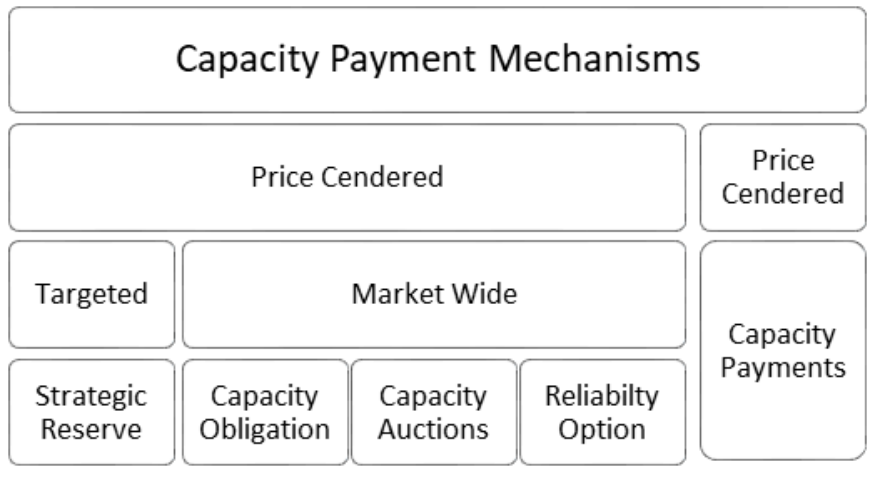

Fig. 1. Classification of capacity mechanism types

Although the targeted mechanisms cover only certain power plants or technologies, the mechanisms in the electricity market try to establish the system balance by meeting the needs of all capacity providers. An additional distinction is made between the decentralized management mechanisms in which contracts are regulated (eg capacity requirements) and the central mechanisms (eg through capacity tenders) where contracts are centrally provided. There are six major mechanism models under unit-centered and price-centered capacity mechanisms shown in Table I $[22,23]$.

\section{A. Strategic reserve}

It is the type of reserve controlled by a central organization. These establishments determine the reserve capacity required for years. It then provides this capacity through a competitive tender (as a strategic alternative) to the contract. Power plants that have established bilateral agreements cannot participate in the electricity market, which only comes into play if there is a lack of capacity and a lack of capacity according to the predetermined criteria. Strategic reserves are mainly used by Belgium, Germany, Poland and Sweden.

\section{B. Capacity obligation}

The consumer or electricity suppliers involved in the power system have to reduce the amount of capacity or reserve capacity that they need to keep, along with their consumption or supplies in the planning. This is usually done by certificates and licenses issued by capacity providers. Energy providers or consumers face a financial penalty if they do not contract at the required quantity level. In general, these capacity mechanisms are used in France.

\section{Capacity auctions}

The total capacity required for the system is determined years in advance. This capacity is provided by the center of the auction. Energy providers in the system offer a capacity amount that reflects the cost of building new capacity for their payments. Thus, the new capacity created in line with the need is only achieved by joining the energy market. Tenders for the required capacities cover new capacity requirements to reduce existing capacity and not to make investment decisions based on market price signals. In general, this capacity is used by the UK to ensure security of supply. 


\section{Reliability options}

The capacity provider involved in the power system arranges a mutual agreement to provide preference to the consumer or distribution company, which offers the other party the option of providing electricity from a predetermined transaction price. In the preferences offered to the consumer or distribution company, the spot market price uses the rare option option when the option exceeds the trading price of the option. This option is generally used by Italy, where a capacity market is planned based on reliability options.

\section{E. Capacity payments}

Capacity fees and tariffs are determined by the market regulator, which is paid to capacity providers. In spite of the amount of capacity required, the receiving facilities only provide energy by continuing to participate in the energy market. The capacity payments for the production and consumption balance are currently used primarily in Italy, Poland, Portugal and Spain; Ireland is paying for a total capacity across the market.

\section{F. Business Spares}

The business reserve market does not completely eliminate the investment cycle, but it does not completely eliminate it. However, it may have an effect of increasing imports instead of investment in interconnected systems. Basically, the system operator is able to give the signals of the capacity demand early, just before the energy market, by providing high value.

TABLE I. CHARACTERISTICS OF APPLIED CAPACITY MECHANISMS

\begin{tabular}{|c|c|c|c|c|c|c|}
\hline $\begin{array}{c}\text { Title } \\
\text { Audit }\end{array}$ & $\begin{array}{c}\text { A } \\
\text { Yes }\end{array}$ & $\begin{array}{c}\text { B } \\
\text { Yes }\end{array}$ & $\begin{array}{c}\text { C } \\
\text { No }\end{array}$ & $\begin{array}{c}\text { D } \\
\text { No }\end{array}$ & $\begin{array}{c}\mathbf{E} \\
\text { Yes }\end{array}$ & $\begin{array}{c}\text { F } \\
\text { Yes }\end{array}$ \\
\hline $\begin{array}{l}\text { Supply } \\
\text { efficiency }\end{array}$ & -- & + & ++ & + & - & \pm \\
\hline Applicability & ++ & + & \pm & + & ++ & ++ \\
\hline $\begin{array}{l}\text { Market } \\
\text { compatibility }\end{array}$ & + & \pm & + & - & + & + \\
\hline $\begin{array}{l}\text { Robustness } \\
\text { against } \\
\text { manipulation }\end{array}$ & + & \pm & + & \pm & \pm & + \\
\hline $\begin{array}{l}\text { Impact } \\
\text { resistance }\end{array}$ & - & \pm & - & + & - & - \\
\hline $\begin{array}{l}\text { Demand for } \\
\text { price elasticity } \\
\text { of demand } \\
\text { Ensuring }\end{array}$ & \pm & + & ++ & + & \pm & \pm \\
\hline $\begin{array}{l}\text { investment } \\
\text { stability }\end{array}$ & \pm & ++ & + & ++ & - & \pm \\
\hline
\end{tabular}

All these capacity mechanisms vary depending on the structure of the electricity market. Since the factor that is the binding factor is the structure of the market, the reserves provided by the bilateral agreements are very important. In addition, the day ahead and day ahead market will have a more stable process with accurate prediction and load controls before real time. Thus, the correct planning of the mechanism is highly effective in energy quality. Voltage disturbances and fluctuations that affect energy quality without impact are frequently encountered in poor network systems. The load currents in the system because non-sinusoidal voltage drops. With this effect, energy quality deteriorates [24]. On the basis of the voltage distortions, the supply demand imbalance is due to the production and consumption estimates, which are generally not done correctly. The most important factor affecting the unrealized estimates is the renewable production capacity.

\section{EXISTING EU CAPACITY MECHANISM PRACTICES}

In the case of limited capacity in power systems, a system with no existing installed capacity (as MW) may be created to meet the service demand at a given time. In such a system, there are two important concerns regarding the participation of intermittent and variable renewable energy resources in capacity mechanisms. The first is the ability to be present when needed, and the second is the negative impact on the economic signals. A system with a capacity limitation attracts more attention in the world.

In a capacity-constrained system, time dependence of supply makes the cut-off an important factor. In such a system, there is a possibility that renewable resources may not be used during the famine. Therefore, the flexibility of such resources makes it harder to evaluate the actual contributions to improve supply security.

With all the developments, it is possible to reduce the capacity prices and create a negative impact on the economic signal by joining the renewable energy sources that have been supported under the current conditions in the capacity markets. As a result of this development, the capacity mechanism may offer an option to provide sufficient wages to overcome the $\breve{g}$ missing money problem traditional and to provide an adequate incentive for the existing traditional capacity or new investment. Therefore, measures should be taken due to the risk that the capacity mechanism will be ineffective in achieving the final policy objectives. One way to address the concern about the artificial reduction of market price signals can be achieved by modifying renewable support programs to accept revenue streams derived from capacity mechanisms.

The capacity mechanisms used and / or deemed necessary in power systems directly affect competition between producers and consumers in the EU electricity market. This competition often requires state aid, which requires it to be subject to EU state aid rules. For the period of 2014-2020, the principles and principles of state aid for environmental protection and energy, which are organized within the framework of forward planning, explain the items of the programs and drafts for the evaluation of capacity mechanisms [25]. If the planned capacity mechanisms are over 15 million euros per project, they should notify the European Commission. The Commission considers the proposed capacity mechanisms based on six criteria. These criteria are listed below. 


\section{A. Criteria 1:}

Measures should pursue the common goal, ie the problem of short or long-term production adequacy needs to be solved. Measures are mainly divided into two groups, of which shortterm measures generally support the maintenance of existing backup capacities, while long-term measures encourage new investments and plans for the power system. The capacity mechanism should pay not only the electricity produced but the required capacity. The analysis of the unreachable energy against the production capability should be in accordance with the ENTSO-E estimations and the European production adequacy estimates.

\section{B. Criteria 2:}

The necessity of the capacity mechanism, the underlying causes of the existing problems, especially the identification of possible market failures and regulatory barriers, needs to be resolved. In addition, alternatives to the capacity mechanism will be examined.

\section{Criteria 3:}

Plans for capacity mechanism should not be independent of technology. Direct use of intelligent systems in decisionmaking systems. It should also be impartial between the participants involved in the system and the investors. It is also important to consider the development of connections.

\section{Criteria 4:}

The most fundamental mechanism should not have a negative impact on competition and trade movements. Thus, it should not interfere with the investment in the interconnections. In particular, it should not interfere with the functioning of the market match. The energy market should be open to all participants and the dominant situations should not be strengthened. It should also support low carbon technologies, which are generally considered in energy production planning, in the capacity mechanism.

More effective allocations should be made by working with Member States to ensure that the capacity-building commission complies with state aid rules for existing and planned capacity mechanisms.

\section{E. Criteria 5:}

It is important to make decisions based on cost-benefit analysis in planning as well as system reliability and sustainable energy. It should also encourage the costs to be paid or on measures that do not involve standard commercial risks.

\section{F. Criteria 6:}

Measures taken for system protection and energy sustainability should be proportionate. For this purpose, storage systems should be provided with the latest technologies and new applications such as pumping application should be preferred.

\section{ACADEMIC ANALYSIS AND EXPERT OPINION}

The development of renewable resources around the world can have a profound impact on revenues for traditional producers and change the balance of energy and capacity market incomes, creating uncertainties in production forecasts. There are three main reasons for this effect on conventional plants. Firstly, intermittent and changed renewable resources reduce conventional generator revenue from the amount of electricity that is expected to be sold. Then, intermittent renewable sources reduce the cost of conventional generator revenue at low prices or plan energy directly to the markets, regardless of marginal cost. Finally, increased flexibility requirements increase costs resulting from more variable operations for traditional manufacturers. All of these effects drive traditional generators to reduce energy revenues. Consequently, restructured markets with a larger proportion of intermittent and variable renewable energy production should have higher capacity payments than those with nonintermittent renewable energy generation. This requires a mechanism for serious capacity planning.

In this study, a special effort has been made to evaluate the effects of capacity mechanisms on trade in the energy market. A large-scale sector survey was initiated on November 30 , 2016 as a component and stage of clean energy planning, and a report was published as a result of the study, which is the first and only research focusing on the industry sector. It has been prepared based on an analysis of the existing or planned 35 capacity mechanisms of the EU member states, which report that member states often do not adequately assess the capacity mechanisms for their needs. The report also concluded that the assessment of cost-benefit assessments and capacity mechanisms is based on the rule. In many Member States, market and legal failures hamper the price signals needed to ensure appropriate levels of supply security. Therefore, he emphasized that the report should be accompanied by market reforms in accordance with the capacity mechanisms. The report identified that most of the capacity mechanisms offered by Member States were not designed to address a clearly defined problem with regard to security of supply. Thus, member states have not sufficiently assessed the situation on security of supply. They have also failed to provide capacity mechanisms for a security that is always justified for supply security.

This study summarizes the ways of improving the design of capacity mechanisms as outlined below:

- The capacity mechanism must match the requirements in the specified power system. While long-term competence is best handled by a market-wide mechanism, transient measures, such as strategic reserves, require transitional measures.

- For regionally limited production sufficiency issues, it is foreseen that improving network connections and adapting the geographic boundaries of the offer areas will probably provide an appropriate solution.

- In some rare cases, payments made to reduce electricity consumption may be appropriate to promote flexible demand. However, there is another point to note that this energy should not turn into subsidies for overconsumption. 
- The cost paid for the capacity mechanism is determined by market conditions, which should be used in a competitive process to determine.

The capacity mechanisms obtained should be open to the participation of capacity producers in neighboring countries. Thus, domestic and foreign capacities and interconnections can be promoted, which also reduces system costs.

In the literature, market prices are currently faced by market and legal failures as the market prices do not meet the fixed cost of traditional production capacity, which affects the price and load factors of electricity demand, electrical ceiling prices and renewable electricity sources defined as variable. This situation leads to the failure to make new investments and to close the existing power plants. Within the scope of this study, the analysis of the situation analyzed, the examination of new capacity mechanisms, and the non-coordinated national capacity mechanisms, may disrupt the market and competition and hinder the completion of the internal energy market. National support given to non-economic power plants may affect price formation, but may hinder the transition to a lowcarbon economy. In addition, there are non-market capacity mechanisms, which may lead to insufficient capacity investments. For this reason, non-market mechanisms may cause competition to deteriorate.

External capacity will be capacity without participation in the network, which will have minimal impacts on markets and investments, and capacity and capacity will change for the country. This study concludes that only the price signals from the energy market need to be taken into account if capacity investments are not made in time to the required production capacity. As there is currently no EU-wide capacity mechanism program, priority should be given to harmonized capacity mechanisms at the regional level. In 2016, the report was prepared by the International Energy Agency (IEA), which concluded that capacity mechanisms could play an important role in providing resource capacity in these liberalized markets. In addition, according to this report, an optimally designed capacity is based on three main components of the market:

- A predetermined demand level should be determined based on the assessment of resource qualification needs,

- Provide a working mechanism for price discovery,

- Create a well-defined capacity product that is technologically undefined and compatible with current innovations,

Well-designed capacity mechanisms should be provided in line with the targets set, which can help solve the problem of lost money without breaking the wholesale energy markets. IEA considers that properly designed wholesale electricity markets are a prerequisite for the functioning and process of capacity markets. It acknowledges that there are benefits in favor of the mechanism by ensuring that external cooperation is ensured by ensuring that regional cooperation moves beyond the boundaries of capacity, without the need to fully harmonize capacity mechanisms.
The report, prepared in 2016, focused on capacity mechanisms and carbon emissions, which were published by the Institute for Overseas Development. It is aimed to reduce the share of existing and planned capacity mechanisms, depending on fossil fuel power plants in the EU and the US, which will undermine carbohydrates. As a result, the implementation of the capacity mechanism is based on political motivations rather than strictly analyzing its needs. This study shows that governments should adopt a large-scale system to support decarbonization. This result uses market design to improve energy quality and improve system reliability. It also includes a detailed analysis of the role of demand-side management in the capacity mechanism, the state of the economically competitive market, optimum storage to ensure low carbon flexibility, and reliability issues that explain interconnection. New investment decisions simulation in electricity markets reveals that both capacity mechanisms and limited pricing are equally effective when investors are ready to take risks. It also determines that investors are more effective in risk avoidance than capacity mechanisms.

Together with the Ministry of Economic and Financial Affairs of the State, the Ministry of Energy conducts research, which is about competition policy and internal energy market. In preliminary studies, a non-discriminatory and competitive market design is proposed for capacity mechanisms. It is recommended to ensure that energy providers in all Member States are open to the market and that the price paid for capacity is determined by a competitive process. Clear rules have been advocated for the deployment of strategic reserves, which should not be used to keep energy prices in the market low or to strengthen their positions.

\section{RECOMMENDATIONS AND ROADMAP FOR CAPACITY MECHANISM}

Energy capacity markets need to be examined in the context of increasing and / or changing renewable energy levels. There are significant differences between the incentives for operational performance provided by States, methods for calculating qualified capacity for variable renewable energy and energy storage, and demand curves for capacity. In addition, there are big differences in capacity market swap prices for production. In this study, it is argued that electricity market design should continue to develop in order to obtain cost-effective policies for resource adequacy.

New capacity investments can be realized by providing capacity signals when market-based supply security solutions are implemented. With these solutions, the capacity demand is expressed in a clear and explicit way, rather than implied by the signals of the price of electrical energy, reducing the investment risk of the manufacturing companies and providing higher supply security and lower price volatility benefits for the consumers. From the six different capacity mechanisms we have examined, it seems that the most effective solution is the capacity requirement mechanism. However, Turkey needs to be adapted to the market structure of the electricity market based on bilateral agreements. The central tenders and bilateral agreements of trust contracts seem to be more untested and innovative solutions. Emergency supply security 
as a market-oriented solution with having to provide new capacity investment in the capacity of Turkey mechanism for electricity market practice fast, easy and inexpensive should be evaluated for applicability. From this perspective, the establishment of the Pennsylvania-New Jersey-Maryland type capacity market is costly and time consuming.

The ultimate solution for long-term security of supply in Turkey electricity market, while in that direction, the easiest and fastest solution to meet the immediate capacity needs in the short term, all retail companies to estimate fixed quantity made according to the load and spare capacity in addition to the optional transitional contracts, such as $15 \%$, providing or to impose an option contract. In the future, it is useful to establish forward capacity market to complete the forward electricity market. More detailed examination of these issues and to produce the original market-oriented solutions to Turkey and supply security must be implemented.

The availability of the electricity market has been characterized by market interventions that have been freed from long-term equilibrium in the market. The most important issue among these interventions is the policy-driven expansion of renewable production capacity, especially based on solar and wind. Renewable capacity at the installed powers is characterized by operational and local characteristics, which are substantially different from the convective production capacity. At the same time, conventional plants need to be moved away due to the moratoriums on life, falling profitability, carbon emissions and nuclear energy. It is imperative to invest in the new capacity to meet the demands of a new electrical system, with the share of renewable and low carbon emission capacity for new technologies.

In addition to these developments, there are concerns about the ability of market models, such as the global target model, to provide adequate investment incentives. Therefore, the current electricity market model, which is the current investment climate, has many difficulties due to a number of policies and market uncertainties, which are summarized below.

- Operation reserve Uncertainties: In case of unforeseen events in power systems, these events can be both failure and supply-demand imbalance, energy sustainability in the system should be ensured. In interconnected systems, each generation plant involved in the grid shall maintain a portion of its capacity as a spinning reserve, defined as the operating reserve. Thus, if necessary, the required amount of energy should be provided with this reserve capacity.

-Uncertainties in climate policy: Climate policy negotiations and design processes for carbon emission are progressing very slowly. This leads to uncertainties in long-term outcomes, particularly in terms of the framework conditions for renewable production, including carbon pricing and targets and criteria, including regional and global policies.

-Uncertainties in the Electricity Market: With the renewable energy, the integration of the electricity market is evolving day by day, but there are some uncertainties about market inferences in the long run, which is influenced by the impact of system challenges, the impact and implementation of flow-based market integration, and the degree of physical market integration. In addition, these uncertainties include the rapid developments in the gas markets in general and the implications for the implementation of gas prices.

- System Uncertainty in regulatory parameters: Some uncertainties in the Energy Market need to be solved, which are the market design situation as a result of changes in mechanisms such as flexibility payments, increased demand-side participation, and improved payment mechanisms for system services.

- Uncertainties for technology and cost development: Technologies need to be developed in line with the developing infrastructure and the needs of the society. At the same time, the modern model should be adopted by introducing these innovations and by changing the price structures and capacity needs and payments significantly. Energy investments and new production stations have infrastructure investment costs for design. The most obvious example is the rapid decline in solar energy in recent years and the large-scale reduction in installation costs. These and similar situations adversely affect investors' investment in new production capacities.

-Economic Uncertainties: There are general economic and financial conditions that affect investors' decisions negatively, which constitutes a major hitch in the energy sector. This situation shows that investors are directly dependent on state policies. Thus, governments need to present new projections for energy investments and planning.

- Uncertainties in Renewable Energy: Production systems such as wind and solar, which negatively affect the production balance in the energy market, directly affect production forecasts, which are a significant problem in the energy sector. This creates difficulties in maintaining the balance between production and consumption. Supply and demand imbalance bring about deterioration in energy quality. This situation, which is directly affected by the frequency, causes disruption to the network. In order to reduce the impact of these deteriorations, mechanisms are designed to meet the capacity requirements required to be carried out. For this reason, governments need to make adequate capacity and operational reserve planning for reserve and energy planning.

\section{CONCLUSION}

As for the capacity mechanism, the long-term capacity of the energy markets remains uninterrupted and inadequate in academic studies. Considering the major changes in the electricity market, it is hard to conclude that the market target 
model of the market target model on an empirical basis has the capacity to deliver capacity.

However, there is a clear consensus on the need to improve the efficiency of the domestic internal market: In the day ahead and day market, the implementation of the capacity mechanism should be increased in line with the target model and the cooperation between the parties in the balancing markets should be increased, which will provide better price signals and a better basis in the long term.

In line with government investments and newly developed regulations, it will provide liquidity along with strong investments and better competition in the markets. Marketbased price signals need to be maintained for renewable energy generation (based on solar and wind power). In addition, new developments and investments in technologies need to be provided with sufficient support to encourage flexible solutions in production as well as in production.

As a result of all these developments and halves, sustainable energy can be provided to increase the energy quality in the power system, which will be achieved by the realization of the capacity mechanism. As system administrators expand the interconnected network in network models, as long as the required reserve requirement is determined correctly, as long as renewable energy production estimates based on wind and solar production are made more accurate and demand side management is well controlled, the capacity mechanism system will be more realistic.

\section{REFERENCES}

[1] C. Batlle, Ignacio J. Perez-Arriaga, "Design criteria for implementing a capacity mechanism in deregulated electricity markets" Utilities Policy Volume 16, Issue 3, September 2008, Pages 184-193

[2] A. D. Baddeley, Denise Scott, Rosemary Drynan and Janet C. Smith, "Short- Term Memory and The Limited Capacity Hypothesis", British Journal of Psychology, Volume 60, Issue 1,

[3] M. Cepeda, D. Finon, "How to correct for long-term externalities of large-scale wind power development by a capacity mechanism" Energy Policy Volume 61, October 2013, Pages 671-685,

[4] Igor K. Shesho, Risto V. Filkoski and Done J. Tashevski, "TechnoEconomic and Environmental Optimization of Heat Supply Systems in Urban Areas" Thermal Science: 2018, Vol. 22, Suppl. 5, pp. S1635S1647

[5] Bingtuan G., Xiaofeng L., Cheng W. and Yi T., "Game-theoretic energy management with storage capacity optimization in the smart grids" J. Mod. Power Syst. Clean Energy (2018) 6(4):656-667

[6] European Commission, 2010. Communication from the Commission: Energy 2020. A Strategy for Competitive, Sustainable and Secure Energy (COM (2010) 639, November $10 \mathrm{~m}$ 2010).

[7] Booz, Company, Newbery, D., Strbac, G., Pudjianto, D., Noël, P., LeighFisher, 2013. Benefits of an integrated European Energy Market. Final Report Prepared for Directorate-General Energy European Commission (July 20).

[8] Creti, A., Fumagalli, E., Fumagalli, E., 2010. Integration of electricitymarkets in Europe: relevant issues for Italy. Energy Policy 38, 6966-6976

[9] Jamasb, T., Pollitt, M., 2005. Electricity market reform in the European Union: review of progress toward liberalization \& integration. Energy J. 26, 11-41.

[10] Pellini, E., 2012. Measuring the impact of market coupling on the Italian electricity market. Energy Policy 48, 322-333

[11] European Commission, 2013. Communication from the commission: delivering the internal electricity market and making the most of public intervention. C (2013), 7243 (November 5).
[12] ACER, 2013. Capacity remuneration mechanisms and the internal market for electricity. The Agency for the Cooperation of Energy Regulators Report (July 30).

[13] RAP, 2013. Capacity markets and European market coupling — can they co-exist? The Regulatory Assistance Project Discussion Draft (March 13, 2013)

[14] D. Finona, V. Pignonb, "Electricity and long-term capacity adequacy: The quest for regulatory mechanism compatible with electricity market", Utilities Policy, Volume 16, Issue 3, September 2008, Pages 143-158, doi.org/10.1016/j.jup.2008.01.002

[15] H. Chao, "Demand Response in Wholesale Electricity Markets: The Choice of the Consumer Baseline," Journal of Regulatory Economics, (2011).

[16] W. Hogan William "Electricity Market Design Energy and Capacity Markets and Resource Adequacy", Mossavar-Rahmani Center for Business and Government John F. Kennedy School of Government Harvard University, 2015

[17] Dario Garozzo, Giuseppe Marco Tina and Dezso Sera, "Comparison of The Reactive Control Strategies in Low Voltage Network with Photovoltaic Generation and Storage" Thermaal Science: 2018, Vol. 22, Suppl. 3, pp. S887-S896

[18] Bin L., Xingchen L., Xiaoqing B. and Zhineng L., "Storage capacity allocation strategy for distribution network with distributed photovoltaic generators", J. Mod. Power Syst. Clean Energy (2018) 6(6):1234-1243

[19] J. Grigorjeva, "Capacity Mechanısms In the Eu: Natıonalızıng Energy Security", Jacques Delors Institut - Polıcy Paper, 134, Berlin, 21 MAY 2015

[20] S. Andoura, J.A. Vinois, "From the European Energy Community to the Energy Union, A Policy Proposal for the short and long-term", Policy Paper No. 107, Jacques Delors Institute, January 2015.

[21] ACER (2013), The Agency for The Cooperation of Energy Regulators, Capacity Remuneration Mechanisms and The Internal Market for Electricity Of 30 July 2013 Pursuant to Article 11 Of Regulation (Ec) No 713/2009

[22] European Commission, DG Energy, Energy Union Package. A Framework Strategy for a Resilient Energy Union with a ForwardLooking Climate Change Policy, February 2015.

[23] European Commission, DG Energy, Energy Union Package. Achieving $10 \%$ electricity interconnection target, February 2015.

[24] S. Biricik, "Design of Unified Power Quality Conditioner for Power Quality Improvement in Distribution Network", Balkan Journal Of Electrical \& Computer Engineering, Vol. 6, No. 1, February 2018

[25] G. Erbach, Briefing, "Capacity mechanisms for electricity", European parliament, May 2017.

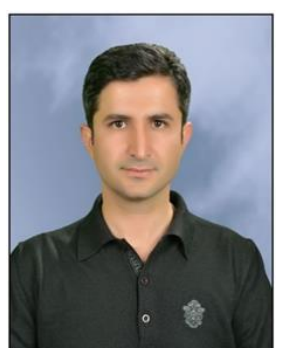

\section{BIOGRAPHIES}

MEHMET RIDA TUR Batman, Turkey, in 1983. He received the B.S. and M.S. degrees in electrical electronics engineering from the University of Marmara, Istanbul, in 2005 and the Ph.D. degree in electrical engineering from Yildiz Technical University, Istanbul, Turkey, in 2018. Now he is work in Batman University as an Assistant Professor. He provides training in power systems and network applications and production systems and network connections. He is working on reliability, conservation, energy economy and energy quality in power systems. Capacity Mechanism, National grid system, smart network requirements for network infrastructure, network integration problem and cyber security studies are continuing. 